\title{
The Rights of Internally Displaced Children: Selected Field Practices from UNICEF's Experience
}

\author{
Subajini Mahalingam, Geeta Narayan, and Esther van der Velde
}

\begin{abstract}
Displacement is a critical humanitarian issue-forty million people are displaced as a result of conflict and other humanitarian crises. Approximately half of the world's displaced persons are children. Children in flight are at greater risk of malnutrition and disease, physical danger, and psychological trauma. Many do not survive. When they do, their ability to lead normal lives is greatly impaired-many have no access to education and health care. This paper examines selected examples from UNICEF's work in the field with internally displaced persons. UNICEF's work with internally displaced children and families focuses on four areas: (1) advocacy, (2) assessment, (3) care, and (4) protection. Conclusions and recommendations are presented drawing from the field practices.
\end{abstract}

\section{Résumé}

Les personnes déplacées représentent un problème humanitaire critique-40 millions de personnes sont déplacées par suite de conflits et autres crises humanitaires. Environ la moitié des personnes déplacées dans le monde sont des enfants. Les enfants en fuite sont beaucoup plus vulnérables à la malnutrition et aux maladies, aux dangers physiques et au trauma psychologique. Beaucoup d'entre eux ne survivent pas. Ceux qui s'en sortent se retrouvent avec des chances diminuées de pouvoir vivre une vie normale-beaucoup d'entre eux n'ont pas accès à l'éducation et aux soins de santé. Cet article examine des exemples sélectionnés $d u$ travail accompli sur le terrain par UNICEF auprès des personnes déplacées. Le travail de UNICEF avec des enfants et des familles déplacés est axé autour de quatre domaines: 1) la défense de leurs droits ; 2) l'évaluation; 3) le soin; et 4 ) la protection. Des conclusions et des recommandations basées sur la pratique sur le terrain sont aussi présentées.

\section{Introduction and Background}

$\mathrm{D}$ isplacement is one of the critical humanitarian issues of our time. Today about one in every 150 people on earth - a total of forty million-is displaced by conflict or human rights violations. Internally displaced persons (IDPs), those who remain within their own borders, constitute two-thirds of the total. Approximately half of all displaced persons - twenty million-are children. ${ }^{1}$ The impact of displacement on children cannot be underestimated: many die within the first days and weeks of displacement due to malnutrition and diseases, especially measles, diarrheal diseases, respiratory infections, and malaria. Children in flight are exposed to physical danger-they may be separated from their families, physically abused, exploited, or abducted; many internally displaced children lose their chances of getting an education, proper nutrition, and health care.

The purpose of this paper is to highlight selected examples from UNICEF's experience working with IDPs in a range of countries, with a view to identifying lessons that could be used to improve future work in this area. It is hoped that the paper will be a starting point for further reflection and analysis by the international community on current initiatives designed to improve the lives and fulfill the rights of IDP children. 


\section{The Situation of Internally Displaced Persons}

Internally displaced persons are defined as those who have been forced to flee their homes of habitual residence, in particular as a result of or in order to avoid the effects of armed conflicts, situations of generalized violence, violations of human rights, or natural or man-made disasters, and who have not crossed an internationally recognized border. ${ }^{2}$ One issue which remains unaddressed by this internationally accepted definition of IDPs is the question of when one's status as an internally displaced person ends; governments, humanitarian organizations, and IDPs themselves all have different interpretations of when displacement (or the effects of displacement) ends. The question of definition has implications for IDPs' access to limited resources, humanitarian agencies' response to emerging/recurring crises, the implementation and enforcement of national legal standards, and the long-term stability and identity of IDPs.

The internally displaced are often more vulnerable than those who choose to remain in their places of origin since they are separated from almost all of their usual support systems. Without the structure and nurturing environments of their home communities, they are more susceptible to arbitrary action by those claiming authority, more liable to suffer forced conscription or sexual abuse, and more regularly deprived of food, water, health care, and other essentials. The internally displaced exist in a legal limbo and are often relatively invisible, even though human rights laws and domestic standards apply equally to them. Though they remain under the jurisdiction of their own government, that government may be unwilling or unable to provide protection and services to facilitate access by others. The displaced may be concentrated in camps or large groups. They may need to locate in urban perimeter housing, with relatives, scattered within the general population, or in hiding, further diminishing visibility and access.

An estimated half of all internally displaced persons are children, uprooted during a particularly vulnerable period of their lives. ${ }^{3}$ Repeated displacement can increase mortality rates by as much as 60 per cent. ${ }^{4}$ Conditions of displacement put at high risk the entire range of rights guaranteed children by the Convention on the Rights of the Child (CRC), including survival, protection, and development. Displaced children may be denied the right to education due to a lack of proper documentation, inability to pay school fees, or their status as non-residents of the area. In Mongolia, many displaced children do not have access to education for these reasons. In Sudan, while malnutrition rates in famine areas decreased, they doubled among the IDP population in $1999 .{ }^{5}$

In addition to difficulties faced by all displaced children, particular groups of children may confront especially traumatic conditions. These include unaccompanied minors, child soldiers, sexually exploited children, children who have witnessed great trauma, girls, and children with disabilities. For example, in Mozambique, displaced children who became soldiers experienced additional threats to their well-being, and required special activities to help them reintegrate into the lives of their families and communities after the end of the conflict. In addition to increasing immediate risks to children, displacement has an effect on children's long-term development, increasing the risk of poverty resulting from the loss of land, inheritance, or other legal rights; incarceration or discrimination; and inability to resume schooling.

\section{The International Response}

The international response to the internally displaced has historically been fragmented and inadequate. However, the international community has recently taken significant steps to improve its response to IDPs, in terms of institutional and operational coordination.

Under international human rights law, internally displaced persons are guaranteed the same fundamental rights and freedoms as the non-displaced. However, displacement often results in greater vulnerability to human rights violations and less ability or willingness by authorities to monitor and enforce compliance with legal standards.

In 1992, as the international community began to more fully appreciate the situation of IDPs globally, the UN Secretary-General appointed Dr. Francis Deng as his Representative on Internally Displaced Persons. As part of his mandate, Dr. Deng has conducted extensive research into the issues and challenges facing IDPs and the legal framework for their protection, and has undertaken several country-specific missions to monitor the situation of IDPs directly. One of Dr. Deng's most significant contributions has been the development in 1998 of the UN Guiding Principles on Internal Displacement, based on his research into the existing legal protection framework for IDPs.

The Guiding Principles represent an attempt to fill an identified gap in international law. They consolidate into one document the relevant rights and norms applicable to IDPs and provide a practical tool for implementation for governments and humanitarian organizations. Although not legally binding themselves, the Guiding Principles are based on international legal standards and principles which are binding. The publication of the Guiding Principles is a useful step in increasing governments' accountability for IDPs and in bringing coherence to the international community's actions vis-à-vis IDPs.

The Guiding Principles specifically mention children, expectant mothers, mothers with young children, and 
female heads of households as groups that should be entitled to special protection and assistance by virtue of their unique needs or vulnerabilities. Displaced children are accorded special protection in several of the principles, including principle 11 (protection from forced labour) and principle 13 (protection from recruitment and participation in hostilities). Children's right to education is recognized in principle 23, with a special emphasis on women and girls. Taken together, the Guiding Principles provide a strong, comprehensive normative framework for the protection and assistance of internally displaced children.

Motivated by a desire to strengthen the international response to IDPs, the Inter-Agency Standing Committee (IASC) of the UN established a Senior Inter-Agency Network on Internal Displacement in July 2000. Consisting of focal points from the IASC member organizations, including UNICEF, the Network has a mandate to review selected countries with internally displaced populations, and to make proposals for an improved international response to their needs, including improvements in the inter-agency approach to IDPs. Since its establishment, the Network has undertaken field visits to Afghanistan, Angola, Burundi, Colombia, Eritrea, and Ethiopia. The Network identified a number of areas in which the international response has been less than adequate. It found great inconsistency in defining and counting IDPs in different countries; age and sex-disaggregation of data on IDPs is very weak. Many governments fail to honour their responsibility to fully meet the protection and assistance needs of IDPs; as a result, assistance provided by international agencies can inadvertently substitute for government action. The response to IDPs' protection needs at the field level, coordinated by the UN Resident Coordinator/ Humanitarian Coordinator, has not been consistent. Part of the reason for this has been a lack of sustained donor funding to IDP issues, especially to fill the "gap" between humanitarian assistance and longer-term development assistance into which IDPs often fall. The Network also identified the need to strengthen the UN system's capacity, both at field level and at Headquarters, to meet the needs of IDPs.

Partly in response to the Network's recommendations, a special unit for IDP issues is being set up in the UN Office for the Coordination of Humanitarian Assistance (OCHA). The unit, which will be operational in January 2002 with staff seconded from UN agencies and NGOs, is tasked with monitoring situations of internal displacement globally; undertaking systematic reviews of selected countries and proposing revised approaches; providing training, guidance, and expertise; mobilizing resources to address the problem of shortterm funding by donors for what are essentially long-term issues for IDPs; advocating globally on behalf of IDPs; and developing further inter-agency policy on IDP issues.
UNICEF welcomes the establishment of the IDP Unit within OCHA, not only because it will contribute to strengthening inter-agency coordination around this critical issue, but also because it may, through improved coordination and resource mobilization, increase the quality and quantity of activities to protect and support IDP children. The Unit may also act as a catalyst to address the other major constraints humanitarian organizations have faced in their work with IDPs, namely, lack of safe and unhindered access to IDPs, an absence of political commitment to address IDP issues (i.e., denial by governments of the existence of IDPs within their borders), staff safety and security, and the dire shortage of resources to meet the needs of IDPs beyond the immediate life-threatening crisis which forces them to flee their homes.

\section{UNICEF's Response}

Within the broader UN system response to IDPs explained above, UNICEF aims to address the needs of IDP children. Using the Convention on the Rights of the Child, international law, and the Guiding Principles on Internal Displacement as its starting point, UNICEF strives to ensure that children displaced under emergency conditions have the same rights to survival, protection, and development as other children. UNICEFs work for internally displaced children does not, of course, take place in a vacuum. The support of its partners, both governmental and non-governmental, local and international, is critical in ensuring the success of UNICEFs efforts to support and protect IDP children. UNICEFs work for internally displaced children can be grouped into the following four areas: advocacy, assessment, care, and protection.

Advocacy for IDP Children. UNICEF seeks to advocate at the community, national, and international levels to ensure that the special needs of displaced girls and boys are consistently brought to the attention of national leaders, international organizations, the media, donors, parties to the conflict, and other audiences. Effective advocacy should be built on accurate data collection, assessment, monitoring, and reporting and may include: (1) regular reporting on the conditions of the displaced; (2) public education efforts internally and abroad; (3) engagement of the media; (4) preparation of publications or videos; (5) actions to strengthen the Convention on the Rights of the Child (CRC); (6) making IDP communities themselves aware of their rights; (7) representations to national authorities; (8) representations to donors; (9) mobilizing partner organizations; (10) advocacy at the highest political level; and (11) ensuring 
that organizations working with the IDP community in general focus on special needs of children. Advocacy work may not be easy. Especially when displacement is associated with membership in an identifiable religious, ethnic or political group that is party to a conflict, advocacy on behalf of the displaced may engender opposition, including from the host government and other program partners.

Assessment. Assessment, monitoring, and evaluation activities are the foundation of sound programs as well as the basis of effective policy and advocacy. Good assessment planning should include the following: (1) the development of indicators of potential displacement; (2) pre-displacement assessments to establish baselines; (3) designing assessment tools with maximum flexibility to take into account the unstable nature of displacement; (4) planning to assess area of return or resettlement; (5) the inclusion of protection issues in assessments; (6) attention to cultural factors during assessments; (7) involvement of displaced including children recognizing limitations to open participation; (8) coordination of assessment efforts with partners.

Care. As part of its work to care for displaced children, UNICEF tries to support them, their families, and communities through actions to restore psychosocial health, maternal and child health care (including the prevention of malnutrition and childhood diseases), schools, water supply and sanitation systems, cultural activities, and self-supporting economic activities at the displacement site. When security can be assured, UNICEF also contributes to mobilizing communities for voluntary return. UNICEF works to promote emergency care for IDP children through a number of different activities, including, for example: (1) preplanning and coordination; (2) anticipation of and budgeting for extraordinary efforts to meet the needs of displaced children; (3) liaising with traditional and non-traditional partners; (4) interventions to support community structures; (5) planning for the possibility of family dispersion; (6) identification of high-risk groups; (7) optimizing the location of displacement; (8) planning for voluntary return, (9) mobilization of resources within the displaced population; (10) education; (11) avoiding stigmatization of the displaced; (12) psychosocial programming; and (13) health programming.

Protection. Internally displaced girls and boys are highly susceptible to violence, exploitation, abuse, rape, and recruitment into armed forces. UNICEF works to protect children from these threats to their well-being, for example, by promoting children as a "zone of peace," increasing their physical security in camps and other settings, and advocating with armed groups about children's rights. Protection activities could include: (1) periods of ceasefire or "days of tranquility" to organize services for children, typically vaccination campaigns, or designated specific access routes as "corridors of peace" for the delivery of needed supplies; (2) the provision of basic identity and registration documents; (3) land-mine awareness; (4) demobilization and reintegration of child soldiers; (5) protection against sexual violence and exploitation; and (6) actions to preserve the cultural and linguistic rights of children.

\section{Selected UNICEF Field Practices}

This section presents some examples from the field with a view to distilling some general lessons and indications of future directions for action in this area.

Advocacy. The objective of advocacy is to ensure that the special conditions and needs of displaced children are consistently brought to the attention of national leaders, international organizations and forums, the media, donors, parties to the conflict, and other audiences through presentations, reports, and other dissemination tools. Advocacy actions may include:

Strengthening Respect for the Convention on the Rights of the Child. The Convention on the Rights of the Child is the starting point for UNICEF's strategy to ensure that IDP children have the same rights as other children. UNICEF promotes a wide range of advocacy, awarenessraising, education and training activities, and widely disseminates information on the Convention on the Rights of the Child and other relevant international standards. The NGO Save the Children and UNICEF held a workshop in Afghanistan in 1999 to mark the occasion of the tenth anniversary of the CRC. The workshop was successful in that local (de facto) authorities, including religious leaders, attended. Humanitarian organizations strongly promoted the workshop within the community and the authorities became very interested. It was made known that the CRC had been translated into the local language and was going to be distributed-but that copies of the translated version would be made available only to those who attended the workshop. Since the authorities did not know what the CRC was about, they decided to attend the workshop. By the end of the training, the authorities began asking questions and showing interest in the issues. ${ }^{6}$

The lack of awareness of children's rights standards constitutes a fundamental obstacle to their implementation. By organizing this workshop and by disseminating the Convention on the Rights of the Child, UNICEF and Save the Children contributed to creating a protection environment in which violations can be prevented or mitigated. 
Advocacy to Target National Leaders. In conditions of internal displacement, national authorities retain the primary duty and responsibility for the well-being of IDPs. Although advocacy can be addressed to multiple audiences inside and outside the country, an important focus of the advocacy should be on those leaders who have the authority and responsibility to address the conditions of the displaced, to prevent abuses of children, to guarantee access to the displaced, to permit IDPs to return voluntarily to their communities, and to address underlying causes of displacement. In Sri Lanka, UNICEFadvocated with the national authorities for the right to education of displaced children. Displaced and returnee children attempting to re-enter school, often in environments where facilities are crowded and teacher shortages are common, can face significant barriers to enrolment. Lack of school uniforms, inability to pay fees, registration or documentation problems, malnourishment, stigmatization, and resistance by local communities already facing shortages all lessen the likelihood that displaced children will be permitted to continue with their education.

UNICEF and program partners in Sri Lanka undertook advocacy campaigns with local and national authorities to break down barriers to education for displaced children. Partly as a result of such advocacy, the Sri Lankan Ministry of Education issued a national circular aimed at lifting registration barriers, and UNICEF financially supported training for teachers regarding the special needs of children who had lost several years of education during their displacement. ${ }^{7}$

Authorities, donors, opinion leaders, and other advocacy audiences concerned about emergency conditions in the country may understand shortfalls in food, medicine, shelter, and other essentials. Few will fully realize the assault on other rights children have, such as the right to education. The result of this advocacy with the national authorities was that their attention was drawn to the right to education of IDP children and the government initiative created an enabling environment for efforts to enrol displaced children in school.

Advocacy at the Highest Political Level. In recent years, the Security Council has adopted a number of important resolutions for the protection of children by armed conflict, such as Resolutions 1265 (1999) and 1296 (2000) on the Protection of Civilians in Armed Conflict and Resolutions 1261 (1999) and 1314 (2000) on Children Affected by Armed Conflict. Many of the provisions in the Security Council resolutions have been used in advocacy efforts in the field. For example, in its Resolution 1355 (2001) on the situation in the Democratic Republic of the Congo, the Council called upon all relevant parties to ensure that urgent child protection concerns, including DDRR (Disarmament, Demobilization, Rehabilitation, and Reintegration) of child soldiers, were addressed in all national, bilateral, and regional dialogues, and that child soldiers were expeditiously demobilized. The Security Council also condemned the use of child soldiers, demanding that all armed forces and groups concerned bring an end to all forms of recruitment, training, and use of children, and called upon all parties to collaborate with the UN, humanitarian organizations, and other competent bodies to ensure the expeditious demobilization, rehabilitation, and reintegration of children abducted or enrolled in armed forces or groups and to allow their reunification with their families. ${ }^{8}$ The Security Council resolutions have been used in advocacy efforts in the field, by UNICEFand others. For example, the resolutions on the Democratic Republic of Congo were used as part of a broader advocacy strategy to secure the release of child soldiers in the Great Lakes Region. This example illustrates how a resolution from the highest political body of the United Nations can exert political pressure and can be used at field level for advocacy.

Advocacy to Mobilize Resources. Interventions reaching the displaced inherently require substantial resources, both human and financial. Yet, the displaced benefit from few dedicated funding streams, and donors may be hesitant to commit resources to populations on the move or in hiding. In part, therefore, advocacy efforts must be planned with the goal of raising donor awareness in order to guarantee needed resources. In addition to raising donor awareness, UNICEF can assist IDP children by encouraging agencies to examine children's issues within their respective mandates. UNICEF, in its discussions with other agencies and NGOs, has reached agreements that other organizations, too, should include in their monitoring activities the rights covered by the CRC. In this way, it is possible to leverage resources from non-child-specific humanitarian organizations to improve the situation of displaced children. Resources well spent are, therefore, necessarily focused on initiating and coordinating activities by other actors. ${ }^{9}$

Although more than 50 per cent of humanitarian response is intended for children and women, children's issues are often compartmentalized within humanitarian agencies. The mobilization of resources among UN agencies creates a focus on children and women within the humanitarian response, generating better coordination within and between agencies and making more resources available for children and women.

\section{Assessment}

The circumstances of displacement make difficult the collection of accurate data, especially in conditions of 
conflict or repeated displacement. Determining the status of internally displaced children may require special efforts to overcome limits to access, uncertain legal standing, or simply difficulty in finding displaced children and following their condition over time. Planning for and allocating resources to accurate, timely, and current assessment are critical to effective interventions on behalf of internally displaced children.

Baseline Assessments and Indicators of Potential Displacement. In Colombia, prolonged conflict and instability leave many communities prone to displacement. A Colombian research institute, Consultorio para los Derachos Humanos y el Desplazamiento (Human Rights and Displacement Consultancy or CODHES), with support fromUNICEF, the European Community Humanitarian Office (ECHO), and other international organizations, developed an early warning system that could be used to indicate potential displacement. Using communitylevel "sentinel sites," they gathered indicators that suggest increased likelihood of displacement within a given geographic area. The data was shared with community leaders, officials, and organizations working with the displaced in order to generate prevention measures or to spur contingency planning activities where necessary. In addition, the early warning systems helped establish baselines to measure the effect of program interventions intended to benefit internally displaced persons. ${ }^{10}$

Knowledge of the risk of displacement can help prevent displacement, limit its scope, or at a minimum assist in an effective emergency response. Planning ahead can help ensure the procedures that take into account children's needs and protection concerns, which can otherwise be forgotten in the chaos of an emergency evacuation. In this case, the information was shared back with community leaders and organizations, allowing them to mobilize in preparation.

Assessing IDP Sociodemographics. In 1996, UNICEFin Angola, along with the United Nations Development Programme (UNDP) supported the government's National Institute of Statistics (NIS) in conducting a multi-province sociodemographic study of the displaced population in Angola. This was done with the co-operation of the National Union for the Total Independence of Angola (UNITA). Part of the success of the study was the multi- level approach which involved the participation of all the actors on the ground-including nonstate actors such as UNITA. This was crucial to get a complete picture of internal displacement in areas both under government and non-government control.

Prior to this data collection activity, information on the over one million displaced persons in Angola was fragmentary, especially with respect to location and condition of displaced persons. Meeting issues of care, protection, and return proved difficult given such sparse data. The results of the assessment helped to bridge this gap. More significantly, agencies were able to identify concentrations of women, teenagers, and girls by looking at the data in relation to age and sex. ${ }^{11}$ Such a disaggregation of data is extremely important for isolating statistics on children and their caregivers (primarily women). In the Angolan study, the information allowed for a more precise targeting of program efforts aimed at women's status and needs (and, as a consequence, that of children). It also stressed the importance of ensuring women's participation in decision-making processes affecting the Angolan displaced. The exercise thus illustrates how good assessment can help in the design of targeted and effective programs.

Coordination of Assessment Efforts. During emergencies when thousands of people may be displaced, conducting situation assessments can be expensive, difficult, and time-consuming. To maximize available resources and therefore efficiency, prevent duplication of work, and avoid conflicting or incompatible data (which tends to occur as agencies respond to their separate notions of the emergency), efforts should be coordinated. UN and other agencies should agree on and set common standards for data collection to ensure greater inter-agency compatibility. They should also coordinate their activities such as initial assessments and establishment of monitoring systems, so agencies complement each other in their work.

In Burundi, UNICEF, the World Food Program (WFP), the Food and Agriculture Organization (FAO), representatives of the Ministries of Health and Agriculture, and NGOs working in the country held a workshop to discuss information needs related to food security. ${ }^{12}$ The Guiding Principles on Internal Displacement set forth the right to an "adequate standard of living," which includes "safe access to essential food...." However, malnutrition and food insecurity were high among displaced communities in Burundi, with 15 to 24 per cent of children under five malnourished. ${ }^{13}$ Malnutrition compounded with instability of displacement leaves children unable to resist attack by disease and by infection from poor sanitation and contaminated water supplies, increasing risk of death by eight times. Tackling the problem effectively required a collaboration of efforts, especially among the UN agencies. The inter-institutional consultation brought together stakeholders and defined standard mechanisms and appropriate data gathering techniques to assist with appropriate food security and nutrition strategies. The workshop made great strides to ensuring quality assessments and thus targeted programming for the delivery of assistance. 


\section{Care}

Care of internally displaced children focuses on all activities that promote the physical and psychological well-being of a child. To this end, UNICEF, through its programming, collaboration and advocacy, attempts to ensure that nutrition, water, hygiene, health, psychosocial, education, and non-food relief services reach children. This is true for all target displaced groups - whether they have relocated away from their communities, are in a transient or camp status, or are on the move.

Emphasizing Family Unity. Maintaining the family unit ensures to a large degree that children have the best physical care and emotional security. Trauma experienced by children upon separation from their family is often greater than the trauma of remaining with the family in an area affected by hostilities. During the war in Bosnia and Herzegovina, and later during the genocide in Rwanda and the subsequent refugee crisis, UNICEFand UNHCRjoined with the International Committee of the Red Cross and the International Federation of the Red Cross and Red Crescent Societies to issue joint statements emphasizing key principles and providing practical guidelines relating to the evacuation of children from war zones. The statements stressed the need to preserve family unity whenever possible and to make every effort to provide adequate protection and assistance to enable families to meet the needs of their children in place.

If separation is unavoidable, careful records of all evacuated children separated from their families should be kept to assist later in reunification. Special emphasis should be placed on keeping siblings together, maintaining communication links with the family of origin, and ensuring that the child's knowledge of his or her culture, language, and religion is preserved. As a practical matter, proper procedures require that personal and family particulars, with photos, should be recorded in a personal profile and history file. Copies of the file should be given to the family, the child (to travel with him or her), the national authorities, the agency to whom the child is entrusted, and a neutral monitoring agency such as the Central Tracing Agency of ICRC. ${ }^{14}$

Coordinating inter-agency efforts is key to success in child tracing. This was proved particularly in the Rwandan case, where 150 humanitarian organizations (including UNICEF and UNHCR from the UN system, ICRC, IFRC, and a number of NGOs) collaborated to successfully reunite sixty-seven thousand children with their families. A key element in the success of the effort was the central database maintained by the ICRC in Nairobi, which allowed for mass tracing.

Empowering Youth. Camps for refugees and the internally displaced can be frustrating places for young people. Bored, anxious, worried, angry, depressed, and traumatized, these youngsters are prime targets for recruitment, violent behaviour, and crime. However, as UNICEF Albania found out, when given a role to play, their energy and capacity can be a great asset to their communities.

During the Kosovo crisis in 1999, many Kosovars fled to nearby Albania seeking refuge. Programs in the six refugee camps near Kukes, Albania, focused on child care, primary education, and health. Adolescents and their specific needs were marginalized. To address this gap, UNICEF and the local Albania Youth Club set up Youth Councils in the refugee camps. Council members organized recreational events for their members, assisted with the integration of new families, and worked for a cleaner and safer camp community. The councils provided activity, but more importantly they gave youth a place to belong to, and a sense of value, meaning, and community in their lives.

The experience of organizing and participating in the Youth Councils gave the members valuable problemsolving and leadership skills. During the reconstruction phase, they returned to play a key part in rebuilding their communities. The program thus helped to build local youth capacity for leadership. ${ }^{15}$

An important element of success in this program was the identification of youth as a group at risk, vulnerable to recruitment, abuse, criminal activity, boredom, and psychosocial issues. However, the Youth Council program was able to steer their energy into tasks that benefited the community. It creatively addressed two challenges by constructively occupying young people while mobilizing them to take on leadership in the community.

Mobile Health Brigades. In Sri Lanka, the deterioration of the health infrastructure in conflict zones, the wide dispersion of the displaced, and concerns about security and transportation made it difficult for IDPs to access adequate health care. UNICEF and program partners addressed this complex problem in part by supporting mobile health clinics that travelled to areas where the displaced were concentrated, to provide basic diagnostic and curative services, immunization, and referrals. ${ }^{16}$ Such basic services can make all the difference in fighting preventable childhood diseases.

Isolated communities face two types of threats: direct attacks or threats from armed groups, and restricted access to important services such as health care, due to insecurity. Both types of threats enter into the community calculations of whether to flee and join the ranks of the displaced and whether, after return, to remain in the home area. Access is even more difficult for communi- 
ties that are uprooted and forced to move not once but several times, as war fronts change. Mobility is often a fact of life for many IDP communities in Sri Lanka. In this field practice, UNICEF sought to address the issue of IDP access to health services. It successfully identified mobility and repeated displacement as a challenge to health program delivery and then addressed it creatively through the creation of mobile "health brigades."

Return of Happiness Project. Since internal displacement in Colombia is often related to violence or the threat of violence, many IDP children suffer emotional and psychological trauma as well as physical deprivation. A UNICEF-supported program to meet the psychosocial needs of these children, called El Retorno de la Alegria (the Return of Happiness), is well regarded.

Notable strengths of El Retorno are its reliance on participation from within the displaced community and its emphasis on building capacity among IDPs. Leaders for therapeutic games and recreational activities, an important component of El Retorno, were recruited from among the internally displaced, and "production groups" were formed among IDPs to produce shoulder bags, toys, and other program material. Training materials for El Retorno de la Alegria included a volunteer's manual that empowered IDP volunteers by providing basic instruction in early childhood development and emphasized the essential role of family and community structures to the child's well-being. Community volunteers were asked to share their experience and training with other displaced or returnee communities, enhancing their status and self-esteem. Of particular note, numbers of displaced teenagers were recruited as leaders of play groups, providing these adolescents with an important anchor to the community at a time of considerable stress in their own lives. ${ }^{17}$

Meeting Psychosocial Needs through Teacher Training. Given the importance of formal education in Sri Lanka, enrolling displaced and returnee children in classes is a high priority for IDP families. UNICEF Sri Lanka recognized that many of these re-enrolled students were still deeply affected by the conflict, and that teachers are in a unique position to observe students facing adjustment difficulties. Training programs for primary school teachers were initiated in co-operation with the Catholic Church to aid them in recognizing signs of psychological stress in IDP children and to guide appropriate interventions or referrals. ${ }^{18}$

Again, the success of the project lies in mobilizing community resources and supporting existing community structures such as the education system. Also, in many communities, it is difficult to approach psychosocial issues, for they are not seen as real problems or people are reluctant to participate for fear of being labelled mentally weak or even mad. The project got over this problem by using education as an entry point for psychosocial work.

\section{Protection}

Protection of displaced children focuses on shielding them from physical and psychosocial harm inflicted by others, such as violence, exploitation, sexual abuse, neglect, cruel or degrading treatment, or recruitment into military forces. Displaced status makes children especially vulnerable to each of these forms of abuse. Protection also refers to those actions that preserve the identity and cultural, linguistic, and inheritance rights of displaced children, since children removed from their home communities are at significant risk of losing these portions of their heritage. Protection activities for IDP children include interventions in the following fields:

Children as "Zones of Peace." An important concept for UNICEF's protection activities is the concept of "Children as a Zone of Peace" to ensure protection of children affected by armed conflict. First formulated in the 1980s, the concept is based on the simple principle that children have the right to protection from violence, abuse, and exploitation at all times-including during armed conflict - and that there is never a justification for targeting or involving children in hostilities. The concept, in its broadest sense, should include a range of measures, such as ceasefires, days of peace, protected humanitarian corridors, and observance of the principles that schools, child centres, and health facilities be inviolate and that the needs of all children be taken into account in peace accords and demobilization plans. One step undertaken by UNICEF has been to declare particular periods of time as "Days of Tranquility" during which services for children, such as vaccination campaigns, are organized, or to designate specific access routes as "corridors of peace" for the delivery of needed supplies. In July 1999, UNICEF East Timor organized one-week-long "Truces for Children" every month for five months. Children were immunized against the major vaccine-preventable diseases and received supplementary food to improve their nutritional status, and pregnant women received antenatal care. In July 2001, synchronized National Immunization Days were launched in Angola, Congo, the Democratic Republic of the Congo, and Gabon with a call for "peace during the mass immunization campaign."

These initiatives, however, must be seen as stepping stones only, with the ultimate goal being permanent, safe, and unhindered access to children for the protection of their rights. ${ }^{19}$ Thus, Days of Tranquility are one 
way to put into practice the fundamental humanitarian principle of access, which recognizes that humanitarian assistance to civilians be granted free and safe passage at all times.

Focus on Identity Issues for Displaced Children. Conditions of displacement, especially if the child is a member of a minority or opposition group, may complicate efforts to register births or otherwise establish the child's identity and full citizenship. Protection activities should ensure that basic identity and registration documents are provided and that government legislation and policies accord full citizenship to displaced children, including those born during displacement, whatever the causes of displacement. In Colombia, as in many environments of large-scale displacement, people forced to flee their homes often encountered problems with identification documents. A co-operative program between UNICEFand the Colombian government agencies, supported by European Community Humanitarian Office (ECHO), organized onestop registration campaigns that made it easier for IDPs to regain identity documents. Materials developed by so-called "registration brigades" were written clearly, in simple language, and widely distributed to encourage participation. Multiple sites were selected for visits by the registration brigades, to overcome transportation difficulties faced by displaced families. Registration programs were targeted at border areas, like the Colombian-Ecuadorian border region, where temporary displacement across national boundaries may confuse registration requirements. ${ }^{20}$

The registration program provided flexibility in terms of location and an opportunity for cross-border registrations. This was an important advantage since people were also temporarily displaced across national boundaries. The registration activities helped to protect identity rights and ensured non-discrimination in future efforts to obtain schooling, employment, participation in civic functions, and other legal rights.

Land-mine Awareness. IDPs in general, and displaced children in particular, are vulnerable to the land mines that are a regular feature of many conflicts today. Displaced communities may find themselves in unfamiliar surroundings with little knowledge of where mines have been placed, and the limited resources available in IDP "welfare centres" may require a widespread exploration of new terrain for water, firewood, or sanitary facilities. Many IDPs must cross active conflict zones in attempts to reach their former properties, either to assess conditions or retrieve resources. Children are particularly at risk, as their curiosity and smaller size cause them to suffer far greater injuries and deaths. In recognizing these realities, UNICEF in Sri Lanka has mounted a land-mine awareness campaign to reach isolated IDP communities using portable flip charts and other transportable instructional material that could be taken to displacement areas. In this way, the scope of the awareness campaign was considerably expanded and a larger number of IDPs were reached by it. ${ }^{21}$ In this case, a mobile awareness campaign proved to be the most effective way to reach a mobile population.

Demobilization and Reintegration of Child Soldiers. Children are more likely to become soldiers if they are poor, separated from their families, displaced from their homes, or lacking access to education. Refugees and displaced children are particularly vulnerable to being coerced into recruitment. In Sierra Leone, rebel groups forcibly recruited many children, potentially creating an enduringly violent substratum of Sierra Leonean society: a large group of young men (and some women) who had spent their formative years on the battlefield. A program to disarm, demobilize, and reintegrate child soldiers was developed and implemented by four humanitarian NGOs: Save the Children Fund, the International Rescue Committee, Caritas, and the Coopi, and was supported by the European Union and UNICEF. After a short demobilization period, the children were transferred to interim care centres closest to their areas of origin for counselling and to begin family reunification.

Reintegrating child soldiers successfully into society can help reduce the potential for future human rights problems in the country by addressing the psychosocial, economic, education, and training needs of a formerly militarized — and potentially still vulnerable — segment of the population. Successful demobilization may also include the promotion of human rights and non-violent means of conflict resolution, so that when these young people assume positions of leadership in the future, they will be able to draw upon these values. The demobilization process, therefore, not only provides essential services to former child soldiers, but also can contribute to broader reconciliation processes. ${ }^{22}$

\section{Conclusions}

The field practices described above give rise to conclusions that have relevance for a number of different IDP situations and for a range of humanitarian and development actors working in the area of children's rights.

Protection and assistance must be seen as mutually reinforcing interventions. Traditionally, the focus has been on providing assistance to IDPs, especially to what are generally seen as "vulnerable" groups such as IDP children; however, the international community is increasingly cognizant of the need to ensure that the populations they seek to assist are also protected from further human rights violations and threats to their safety. For 
IDP children in particular, this means that the international community must seek to ensure that children have a better understanding of the full range of rights-including the right to protection - to which they are entitled. Awareness of one's rights is also a key factor in empowerment.

Because the protection and assistance needs of IDPs are so interlinked, internal displacement should be addressed as part of a broader humanitarian and development strategy. Since displacement is often a key factor behind the need for humanitarian assistance, a broader, systemic understanding of displacement-including the return and resettlement stages-is essential to effective humanitarian assistance. The false divide between humanitarian and development assistance is even more evident in donor responses to displacement-characterized by a lack of understanding of the ongoing nature of many displacement crises and needs, the long-term impacts of what looks to be a short-term problem (especially for internally displaced children), and the relative absence of a longerterm protection strategy for IDPs.

There is an urgent need for improved institutional and thematic coordination on the ground. Especially helpful at the field level will be implementation of the country-specific recommendations by the UN Inter-Agency Network on IDPs and the coordination work of the new IDP Unit within OCHA. Within this context, UNICEF seeks to contribute to raising the awareness and attention of its partners (UN and NGO) to the special needs and rights of displaced children. Through greater attention to IDP children both in the advocacy and allocation of resources by non-child-specific organizations, coordination and complementarity of actions around the thematic area of children can be strengthened.

Of the many different activities needed to protect and support IDP children, assessment is a particularly undervalued area of activity. It is often during the assessment stage that key decisions affecting rights and well-being of children are made, for example, decisions about which types of interventions are most critical for children during and after flight, or where interventions should be targeted to reach the greatest concentration of at-risk children. The early and ongoing availability of sex- and age-disaggregated data is essential to inform these kinds of decisions. A good assessment will also identify the specific challenges faced by different groups of children unaccompanied minors, former child soldiers, separated children, adolescents, girls - as well as the coping mechanisms already in place or being used by the children themselves, and the interventions most appropriate for each group. Finally, assessments also need to address the definition of IDP status - when displacement ends-in order to ensure accuracy of situation analyses.

The participation of internally displaced young people is a critical element in successful project design, delivery, moni- toring, and evaluation. Where interventions have been successful in restoring normalcy or in providing basic services in a sustainable manner, it is youth participation that has often been instrumental. Beyond the immediate impact of better programs, the participation of young people is also a major contributor to rebuilding their self-esteem, increasing their sense of efficacy, and ultimately to aiding in their empowerment.

When providing assistance to IDP children, efforts should be made to recognize and take advantage of entry points to reach children. International and non-governmental organizations may be able to use traditional entry points, such as education and health, to initiate activities in less well-accepted areas such as psychosocial support, recreation or gender-based violence. There may often be more flexibility around broadening the scope of care activities for children, as opposed to adults.

Similarly, creative solutions must be sought in order to address many of the challenges facing IDPs. Their situations are characterized by mobility, among other factors; their mobility may mean that mobile solutions are required. Traditional approaches and solutions to humanitarian assistance are likely to fall short of having a real impact on the lives of IDPs. What is needed are creative, think-outside-the-box solutions to the complex set of challenges facing IDPs. Institutional capacity building may be required to achieve this.

A multi-dimensional approach is necessary in advocacy efforts for IDPs. Not only is it critical to advocate at different levels, but it is also important to target advocacy at different kinds of actors within each level. At countrylevel, for example, advocacy for IDP children should be directed to national authorities and leaders, law enforcement personnel, community structures and leaders, school management structures, the media, non-state actors, the business community, parents, and IDP children themselves.

The preservation of family unity should be a general principle when working with IDP children. The family is often the most effective unit of protection and assistance for IDP children, especially very young children. Family reunification is also among the most important activities for children who have been separated from their families, and can help restore normalcy in a way that few other activities can.

It is hoped that this paper, which attempts to capture some lessons from the field, may prove useful to UNICEF's partners as well UNICEF itself. It is a sad fact that, all too often, lessons are not systematically captured, shared, and incorporated into the work of the international assistance community; in an area of assis- 
tance as urgent yet also as constant as internally displaced children, the need to learn from past efforts is that much more important.

\section{Acknowledgements}

This paper draws extensively upon the excellent work of James Kunder, consultant to UNICEF and author of several UNICEF documents on IDP children and Viktor Nylund, former Project Officer in the Office of Emergency Programs, and from Growing the Sheltering Tree: Protecting Rights through Humanitarian Action, prepared by Diane Paul for the Inter-Agency Standing Committee.

While the authors are affiliated with UNICEF, the views expressed in this paper are those of the authors alone and do not in any way reflect those of UNICEF or its policies. The designations employed in this publication and the presentation of the material do not imply on the part of the authors or the United Nations Children's Fund the expression of any opinion whatsoever concerning the legal status of any country or territory, or of its authorities, or the delimitations of its frontiers.

\section{Notes}

1. Graça Machel, The Impact of War on Children: A Review of Progress since the 1996 United Nations Report on the Impact of Armed Conflict on Children (London: Hurst and Company, 2001), 26.

2. UN Guiding Principles on Internal Displacement.

3. Machel, 26.

4. Machel, 35

5. Humanitarian Appeal for Children and Women in Sudan, Jan-Dec. 2000 (New York: UNICEF, 2000), 1.

6. Field practice 63: "Creating Curiosity in a Topic Is One Way to Get People Interested in Rights Issues," in Growing the Sheltering Tree, Protecting Rights through Humanitarian Action: Programs and Practices Gathered from the Field, Diane Paul (Geneva and New York: Inter-Agency Standing Committee Reference Group on Human Rights and Humanitarian Action, forthcoming).

7. Mission to Sri Lanka with a View to Develop Field Practices to Internal Displacement, UNICEF Office of Emergency Programs Working Paper Series (New York: UNICEF, 1998), 6.

8. Security Council Resolution 1355 on the Situation Concerning the Democratic Republic of the Congo, 15 June 2001, para 14 and 18.

9. Mission to Sri Lanka with a View to Develop Field Practices to Internal Displacement, UNICEF Office of Emergency Programs Working Paper Series (New York: UNICEF, 1998), 7.

10. Field practice 41: "Displacement 'Early Warning Systems' Can Alert IDP Communities and Assist with Contingency Planning," in Growing the Sheltering Tree.

11. Inter-Agency Standing Committee Working Group, Manual on Field Practice in Internal Displacement: Examples from UN Agencies and Partner Organizations of Field-based Initiatives Supporting Internally Displaced Persons (OCHA,1999), 15.
12. Ibid., 42.

13. Machel, 75.

14. Field practice 13: "Guidelines for Evacuation of Children from War Zones Can Prevent Harm Caused to Children by Separation from Families and Poor Planning," in Growing the Sheltering Tree.

15. Machel, 33.

16. Field practice 133: "Mobile 'Health Brigades' Reach Isolated Returnee Communities and Communities at Risk of Displacement," in Growing the Sheltering Tree.

17. Field practice 199: "Meeting the Psycho-social Needs of Displacement-Affected Children through Maximum Use of the Community's Resources, Including Adolescents," in Growing the Sheltering Tree.

18. Field practice 207: "Meeting the Psycho-social Needs of Children through Teacher Training," in Growing the Sheltering Tree.

19. UNICEF Action on Behalf of Children Affected by Armed Conflict (Division of Evaluation, Policy, and Planning Working Paper, 2000), 14.

20. Field practice 158: “Registration Brigades' Can Help Guarantee IDPs the Right to a Legal Identity," in Growing the Sheltering Tree.

21. Mission to Sri Lanka with a View to Develop Field Practices to Internal Displacement (UNICEF Office of Emergency Programs Working Paper Series, 1998), 5.

22. Field practice 200: "Reintegrating Child Soldiers into Civil Society Takes Extra Care but Can Provide Long-lasting Human Rights Rewards," in Growing the Sheltering Tree.

Suba Mahalingam graduated from the University of Toronto with a double minor in History and South Asian Studies. She has worked with Tamil refugee youth in Toronto and is currently working as an intern with UNICEF New York.

Geeta Narayan has worked in the area of children's rights for over six years, and is currently project officer for humanitarian policy and advocacy with the Office of Emergency Programmes at UNICEF New York.

Esther van der Velde has worked for three years in the field of human rights and is currently working as assistant program officer in the Office of Emergency Programmes at UNICEF New York. 